EXATASE TECNOLÓGICAS

V.3 N.3 • Agosto/Setembro/Outubro - 2019

ISSN Digital: 2359-4942

ISSN Impresso: 2359-4934

DOI: $10.17564 / 2359-4942.2019 v 3 n 3$
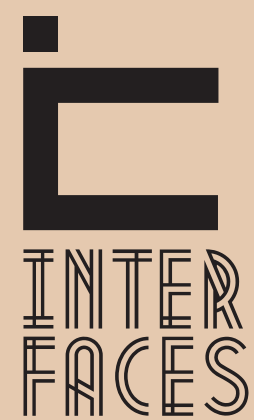

CIENTÍFICAS

\section{PLANO DE IMPLANTAÇ̃̃O DE ÁREAS VERDES PARA AS ESCOLAS MUNICIPAIS DE UNIÃO DOS PALMARES/AL}

PLAN FOR THE IMPLEMENTATION OF GREEN AREAS FOR THE MUNICIPAL SCHOOLS OF UNIÃODOS PALMARES/AL

PLANDE IMPLEMENTACIÓN DE ÁREAS VERDES PARA LAS ESCUELAS MUNICIPALES DE LA UNIĨODOS PALMARES/AL

\section{RESUMO}

Com o ritmo acelerado da vida atual, os indivíduos têm cada vez menos contato com áreas verdes. Crianças e jovens em idade escolar passam pelo menos 5 horas diárias na escola. Pensando nisso, ofertar espaços verdes nesses ambientes favorece a interação entre usuários e meio ambiente. Assim, o presente estudo teve como objetivo geral elaborar uma cartilha de paisagismo para escolas municipais a partir do estabelecimento de diretrizes que contribuirão para a implementação de áreas verdes escolares. Busca-se ainda considerar aspectos sociais, ambientais e econômicos destas unidades, através da promoção de práticas que auxiliarão na implantação e manutenção dos espaços verdes inseridos nas escolas. A metodologia adotada buscou obter resultados qualitativos através de levantamentos bibliográficos. 0 diagnóstico teve como fonte de dados as escolas municipais de União dos Palmares. Foram realizadas análises críticas em relação ao projeto PDDE Sustentável, mostrando que é possível melhorar a qualidade do ensino permitindo contato do aluno com a natureza. A partir dos problemas encontrados, foi possível definir as diretrizes que nortearam este estudo e assim, foi construída a cartilha Paisagismo na Escola, proporcionando um subsídio acessível para que gestores e comunidade escolar possam aplicar na implantação e cuidado com as áreas verdes escolares.

\section{PALAVRAS-CHAVE}

Paisagismo, Áreas Verdes, Escolas Municipais. 


\section{ABSTRACT}

With the fast pace of life today, individuals have less and less contact with green areas. Children and Teens spend less than 5 hours a day at school. With this in mind, from time to time they are always focused on environments and the environment. This present study had as general objective to draw up a landscape primer for municipal schools from the establishment of a direction for the implementation of green school grounds. It is sought according to the social, work and expansion needs, through the promotion of activities that help in the implantation and maintenance of green spaces inserted in the schools. Methodology adopted seeks to obtain qualitative results through bibliographic surveys. The diagnosis was based on data from the municipal schools of União dos Palmares. The Sustainable PDDE was opened in relation to the study of the student with a nature. From the problems that was found, was possible to define a guideline that guided this study. And so, a School Landscaping booklet has been built, providing an accessible allowance for managers and a school community that can be applied in deployment and care as school green areas.

\section{KEYWORDS}

Landscaping. Green Areas. Schools.

\section{RESUMEN}

Con el rápido ritmo de vida actual, los individuos tienen cada vez menos contacto con las áreas verdes. Los niños y jóvenes en edad escolar pasan al menos 5 horas al día en la escuela. Con esto en mente, proporcionar espacios verdes en estos entornos favorece la interacción entre los usuarios y el medio ambiente. Así, el presente estudio tuvo como objetivo general elaborar un manual de paisajismo para las escuelas municipales a partir del establecimiento de pautas que contribuyan a la implementación de áreas verdes escolares. También busca considerar los aspectos sociales, ambientales y económicos de estas unidades, a través de la promoción de prácticas que ayuden en la implementación y mantenimiento de los espacios verdes insertados en las escuelas. La metodología adoptada buscaba obtener resultados cualitativos a través de encuestas bibliográficas. El diagnóstico se basó en datos de las escuelas municipales de União dos Palmares. Se realizaron análisis críticos en relación con el proyecto PDDE Sostenible, demostrando que es posible mejorar la calidad de la educación permitiendo el contacto del alumno con la naturaleza. A partir de los problemas encontrados, fue posible definir los lineamientos que guiaron este estudio y así, se construyó el folleto Paisajismo en la Escuela, proporcionando un subsidio accesible para que los administradores y la comunidad escolar puedan aplicar en la implementación y cuidado de las áreas verdes de la escuela. 


\section{PALABRAS CLAVE}

Paisajismo, Zonas Verdes, Escuelas Municipales.

\section{INTRODUÇ̃̃o}

A vida na cidade trouxe uma condição de menor contato com áreas verdes e o ritmo acelerado da população contribui de forma significativa para o agravamento dessa situação. Para minimizar os efeitos dessa falta de contato com a natureza e sabendo que crianças e jovens em idade escolar passam pelo menos cinco horas diárias no ambiente escolar, ofertar espaços com essas características os levam a estabelecer relações mais naturais e criativas com o meio ambiente. Assim, a intervenção paisagística nas escolas deve ser planejada para atender às necessidades estéticas e de funcionais dos usuários, bem como, para servir de ferramenta às práticas escolares. A vegetação, matéria-prima do paisagismo, pode ser utilizada para educar em diversas matérias, especialmente aquelas voltadas à educação ambiental.

Segundo Pacheco e Sponchiado (2017), para auxiliar os docentes no processo de ensino e sensibilização ambiental, é preciso tornar o ambiente agradável por meio de uma boa vivência com a natureza, fornecendo assim, um rico material para o aprendizado. Nesse contexto, Pontalti (2005), educadora ambiental, diz que "a escola é o espaço social e o local onde o aluno dará sequência ao seu processo de socialização, iniciado em casa, com seus familiares”. É evidente, portanto, a importância da educação ambiental estar inserida no cotidiano escolar, sendo fundamental para a construção do indivíduo. E quanto mais cedo essa prática se iniciar, veremos resultados cada vez mais significativos.

No Brasil, desde 1995, existe um programa intitulado Programa Dinheiro Direto na Escola (PDDE), que destina recursos financeiros para as escolas públicas da educação básica, onde uma das ações agregadas chama-se "Escolas Sustentáveis" . A finalidade desta ação agregada é que as escolas adotem os critérios de sustentabilidade ambiental, baseando assim, seus projetos em equidade social, proteção ambiental e participação democrática. Trabalhando em três eixos de ação passíveis de financiamento, que são, o apoio para criação e o fortalecimento da Comissão de Meio Ambiente e Qualidade de Vida na Escola (Com-Vida), adequação do espaço físico, visando à destinação apropriada de resíduos da escola, eficiência energética e uso racional da água, conforto térmico e acústico, mobilidade sustentável e estruturação de áreas verdes, assim como, a promoção da inclusão da temática socioambiental no projeto político-pedagógico da escola.

Geralmente, as escolas possuem uma área descoberta, principalmente as situadas em municípios do interior do Estado. Algumas com espaços físicos delimitados, muitas vezes desocupados, desvalori-

2 Lançado na IV Conferência Nacional Infanto-juvenil pelo Meio Ambiente no ano de 2013, o Programa Dinheiro Direto na Escola (PDDE) - Escolas Sustentáveis, tem como objetivo construir projetos em escolas de pesquisa e intervenção voltados a sustentabilidade, com base nos recursos financeiros do Fundo Nacional de Desenvolvimento da Educação (FNDE) (SANTOS; GARDOLINSKI, 2016). 
zados e esquecidos. No intuito de ocupar essas áreas, propõe-se a inserção do paisagismo nas escolas, incentivando, dessa forma, a participação da comunidade que pode se apropriar da ideia (LEÃO, 2005).

Ao considerar a escassez de informações que deveriam auxiliar gestores escolares na criação e administração adequada de áreas verdes nas escolas, o estudo teve como objetivo geral, elaborar uma cartilha de paisagismo para as escolas municipais de União dos Palmares, cidade situada na Zona da Mata alagoana; assim, a partir do estabelecimento de diretrizes que contribuíram com a implementação dos mesmos, considerados aspectos sociais, ambientais e econômicos das ações desenvolvidas pelas unidades educativas participantes do PDDE Sustentável; e, por meio da promoção de práticas que auxiliaram na implantação e manutenção do espaço verde inserido no ambiente escolar.

Assim, verifica-se a necessidade de pesquisar e promover práticas sustentáveis a partir da implantação e manutenção de um espaço verde inserido no ambiente escolar, bem como subsidiar os gestores escolares na utilização da verba para correta e adequada execução do projeto de paisagismo nas escolas.

A metodologia adotada no estudo buscou obter resultados qualitativos por meio de levantamentos bibliográficos, os quais discutiram a importância de áreas verdes em espaços escolares e os benefícios que elas trazem para a vida e para o aprendizado dos alunos, sendo essa metodologia desenvolvida por recursos literários, artigos científicos e digitais.

O diagnóstico teve como fonte de dados as escolas municipais de União dos Palmares. Foram realizadas análises críticas em relação ao projeto PDDE Sustentável, mostrando que é possível melhorar a qualidade do ensino, permitindo o contato do aluno com a natureza.

\section{DIAGNÓSTICO DAS ESCOLAS MUNICIPAIS DE UNIÃO DOS PALMARES}

\section{1 ÁREA DE ESTUDO}

O município de União dos Palmares está localizado na Microrregião Geográfica Serrana dos Quilombos, na Mesorregião do Leste Alagoano, abrangendo uma área de $428 \mathrm{~km}^{2}$ a cerca de 70 quilômetros da capital, Maceió (IBGE, 2010).

Ao considerar as regiões administrativas do Estado, o município insere-se na região do litoral norte e possui como limites: ao norte os municípios de São José da Laje, Ibateguara e Colônia Leopoldina, ao sul Branquinha, ao leste Joaquim Gomes e ao oeste Santana do Mundaú. Sua sede municipal está situada a margem esquerda do Rio Mundaú e dista $83 \mathrm{~km}$ da capital Maceió. A altitude da sede do município em relação ao nível do mar é de 155 metros e suas coordenadas geográficas de 09¹0'17,51" de latitude sul e $36^{\circ} 01^{\prime} 16,17^{\prime \prime}$ de longitude oeste.

Fundada em 13 outubro 1831, União dos Palmares é considerada uma das principais cidades de Alagoas, conhecida por ser "A Terra da Liberdade"; pois nela, mais precisamente na Serra da Barriga, foi constituído um dos principais símbolos da resistência ao modelo escravocrata imposto ao Brasil por mais de três séculos.

A cidade é parte integrante da Área Piloto da Reserva de Biosfera da Mata Atlântica (RBMA) e da Área de Proteção Ambiental APA de Murici, detendo ainda o Sítio Arqueológico da Serra da 
Barriga tombado Patrimônio Histórico Nacional em 1988. Possui um núcleo urbano com atividades de comércio e serviços atraentes para os municípios vizinhos, embora a base econômica principal do município seja a agrícola.

A agricultura local é caracterizada pela combinação dos canaviais e pastos para pecuária, com uma produção diversificada "que elevou a cidade a centro policultor, com destaque para a banana, plantada na região do Vale da Pelada”. Em parceria com o município de Viçosa, União dos Palmares forma um polo produtor de proteína animal, responsável por $30 \%$ da produção avícola e $20 \%$ da suína em Alagoas (CAMPOS; PÉRICLES; TENÓRIO, 2006.).

Conforme dados do censo 2010, a população total é de 62.401 pessoas, sendo composta de 30.193 homens e 32.208 mulheres. 0 total da população urbana é de 47.691 pessoas e o total da população rural de 14.710. A exemplo de outros municípios brasileiros a área urbana de União dos Palmares vem crescendo em decorrência, principalmente, do processo de migração rural. 0 resultado desta migração pode ser vista nos bairros Roberto Correia de Araújo (antigo bairro Terrenos), Vaquejada, Mutirão e Padre Donald, locais em que parte de seus moradores trabalham no corte da cana da própria região (CAMPOS; PÉRICLES; TENÓRIO, 2006).

A proporção de moradores, segundo o censo 2010, com acesso ao direito de propriedade própria atinge $71 \%$. Os dados revelam que $29 \%$ da população não possuem residência própria, podendo ser alugado ou cedido. Com relação ao acesso aos serviços de saneamento ambiental os dados do Instituto Brasileiro de Geografia e Estatística (IBGE) registram que em 2010, 80\% dos moradores tinham acesso à rede de água geral com canalização em pelo menos um cômodo e 63,2\% possuíam formas de esgotamento sanitário considerado adequado. Em 2010, 97\% dos moradores urbanos contavam com o serviço de coleta de resíduos e $93,2 \%$ tinham energia elétrica distribuída pela companhia responsável. Com relação aos dados escolares, os mesmos serão tratados no tópico a seguir.

\subsection{ESCOLAS MUNICIPAIS DE UNIÃO DOS PALMARES}

Desde o ano de 2014 a cidade tem desenvolvido programas e ações, visando um melhoramento de sua rede de ensino, com atividades de atualização profissional para seus servidores, reformas e ampliação da rede de ensino, bem como investimento em equipamentos e materiais escolares. Como reflexo do investimento aplicado na educação municipal, o Índice de Desenvolvimento da Educação Básica (IDEB) no município cresceu acima da média estimada para o ano de 2019, saindo de um valor de 3,6 em 2013 para 5,2 em 2017.

A educação infantil no Município de União dos Palmares é oferecida para crianças de dois anos e meio a cinco anos e meio. Já a educação fundamental I para alunos de $1^{\circ}$ ao $5^{\circ}$ ano; e, o fundamental II para alunos de $6^{\circ}$ ao $9^{\circ}$ ano. Existe também o segmento EJA, que é a Educação de Jovens e Adultos para os alunos fora da faixa a partir de 15 anos de idade.

As unidades escolares no Município contam com um quadro de 944 professores; sendo compostas por 25 unidades escolares municipais que atualmente atendem a 12.741 alunos regularmente matriculados. 


\subsection{PROCEDIMENTOS METODOLÓGICOS}

Inicialmente, foi realizada uma apresentação do plano de trabalho à Secretaria Municipal de Educação, na pessoa da Senhora Rimelc Shirley Lins de Albuquerque Pontes Cavalcante, secretária, solicitando permissão para a realização da pesquisa.

Posteriormente foram realizadas as visitas às unidades escolares, apresentando ao diretor (a), a permissão para a realização de pesquisa. Foram feitos registros fotográficos do espaço geral; e, em seguida um diagnóstico da escola. Analisando, presença de áreas verdes, espaços livres e as ações de sustentabilidade já desenvolvidas pela escola.

O levantamento de dados foi realizado em agosto de 2018. 0 tempo de trabalho em cada escola foi variável de acordo com o tamanho da unidade escolar, bem como de sua área verde - existente ou não naquela instituição.

A pesquisa foi realizada em 23 escolas municipais, as quais estão distribuídas da seguinte forma: 12 na zona urbana e 11 na área rural, conforme divisão estabelecida pela Secretaria Municipal de Educação de União dos Palmares.

As escolas José Clarindo Pães e Professora Elizabete Santos foram excluídas do estudo devido ao seu difícil acesso, já que se localizam na área rural, estando a pelo menos duas horas de carro em estradas sem pavimento.

Após as visitas, foram identificados os principais problemas que dificultam a implantação ou manutenção das áreas verdes nas unidades escolares estudadas, como podemos observar na tabela 01.

Tabela 1 - Lista de problemas

\begin{tabular}{|c|c|}
\hline PROBLEMAS & $\begin{array}{r}\text { PERCENTUAL } \\
\text { ENCONTRADO }\end{array}$ \\
\hline Não possuem espaços descobertos & $4,5 \%$ \\
\hline $\begin{array}{c}\text { Há espaços abertos, porém com solo pavimentado em todo o terreno esco- } \\
\text { lar, com materiais impermeáveis. }\end{array}$ & $9 \%$ \\
\hline $\begin{array}{c}\text { Possui problemas com água no verão } \\
\text { (relatam dificuldades no abastecimento). }\end{array}$ & $4,5 \%$ \\
\hline $\begin{array}{c}\text { Possui espaços abertos, porém com 90\% } \\
\text { do solo pavimentado, com materiais impermeáveis. }\end{array}$ & $4,5 \%$ \\
\hline Dificuldade de comprometimento com o cuidado das áreas verdes & $100 \%$ \\
\hline
\end{tabular}

Fonte: Autora do estudo (2018). 
Após as visitas às unidades escolares, foi possível averiguar as potencialidades (TABELA 2) das mesmas, que serviram como base parra construção das diretrizes de implantação de áreas verdes.

Tabela 2 - Lista potencialidades

\begin{tabular}{|c|c|}
\hline POTENCIALIDADES & $\begin{array}{c}\text { PERCENTUAL } \\
\text { ENCONTRADO }\end{array}$ \\
\hline Possuem hortas & $64 \%$ \\
\hline Possuem área verde & $82 \%$ \\
\hline Ajudam na manutenção da horta: Funcionários & $48 \%$ \\
\hline Ajudam na manutenção da horta: Alunos & $43,5 \%$ \\
\hline Ajudam na manutenção da horta: Comunidade (pais de alunos e vizinhos) & $9 \%$ \\
\hline Possuem Galinheiro e usam os excrementos como adubo & $9 \%$ \\
\hline Reutilização da agua dos bebedouros & $13 \%$ \\
\hline
\end{tabular}

Fonte: Autora do estudo (2018).

\subsection{IDENTIFICAÇÃO DAS ESPÉCIES VEGETAIS ENCONTRADAS NAS ÁREAS VERDES ESCOLARES}

As espécies foram identificadas por meio das placas de identificação presentes nas hortas e áreas verdes, bem como com a assistência de servidores das escolas que auxiliam na manutenção e manejo destes ambientes.

As espécies mais recorrentes são as hortícolas, como: coentro, cebolinha, tomate, manjericão e alface. Devido a seu manejo relativamente simples, crescimento rápido e sua utilização para melhoramento da merenda escolar, uma vez que não compõe a lista de alimentos ofertados para a mesma mas que acrescentam sabor aos preparos.

\subsection{ESCOLAS SUSTENTÁVEIS DE UNIÃO DOS PALMARES}

Dentre as 25 unidades escolares, 12 foram contempladas pelo programa PDDE - escolas sustentáveis com a aplicação do recurso no ano de 2017. Receberam entre 8 e 14 mil reais, para emprego em seus projetos ambientais. As ações são variadas, desde a criação de hortas escolares, a construção de sistemas de reutilização de água dos bebedouros, instalação de galinheiros, execução de projeto paisagístico.

As atividades desenvolvidas no PDDE - escolas sustentáveis, são construídas tendo como base nas seguintes linhas de ação passíveis de financiamento: apoiar a criação e o fortalecimento da Comissão de Meio Ambiente e Qualidade de Vida na Escola (Com-Vida); promover a inclusão da temática socioambiental no projeto político pedagógico da escola; adequar o espaço físico, visando a destinação apropriada de resíduos da escola, a eficiência energética, o uso racional da água, o conforto térmico e acústico, a mobilidade e a estruturação de áreas verdes. 
Em cada linha de ação podem ser desenvolvidas uma grande variedade de atividades como: realização de oficinas; aquisição de equipamentos que favoreçam o registro das atividades e acesso à internet (computador e internet banda larga); subsídios teórico-metodológicos e pedagógicos (vídeos, publicações, jogos cooperativos); possibilidade de deslocamentos (em visitas guiadas) para conhecimento de iniciativas relacionadas à sustentabilidade socioambiental na comunidade/cidade em que a escola se situa, visita a museus tecnológicos e experiências bem-sucedidas em áreas de interesse; o uso das ecotécnicas ${ }^{3}$, visando a apropriação pedagógica em diversas disciplinas da escola; gestão de resíduos sólidos, biodiversidade, práticas de alimentação saudável, horta escolar, uso racional de água e energia, dentre outros.

Figura 1 - Ações desenvolvidas com recurso do PDDE Sustentáveis nas escolas de União dos Palmares
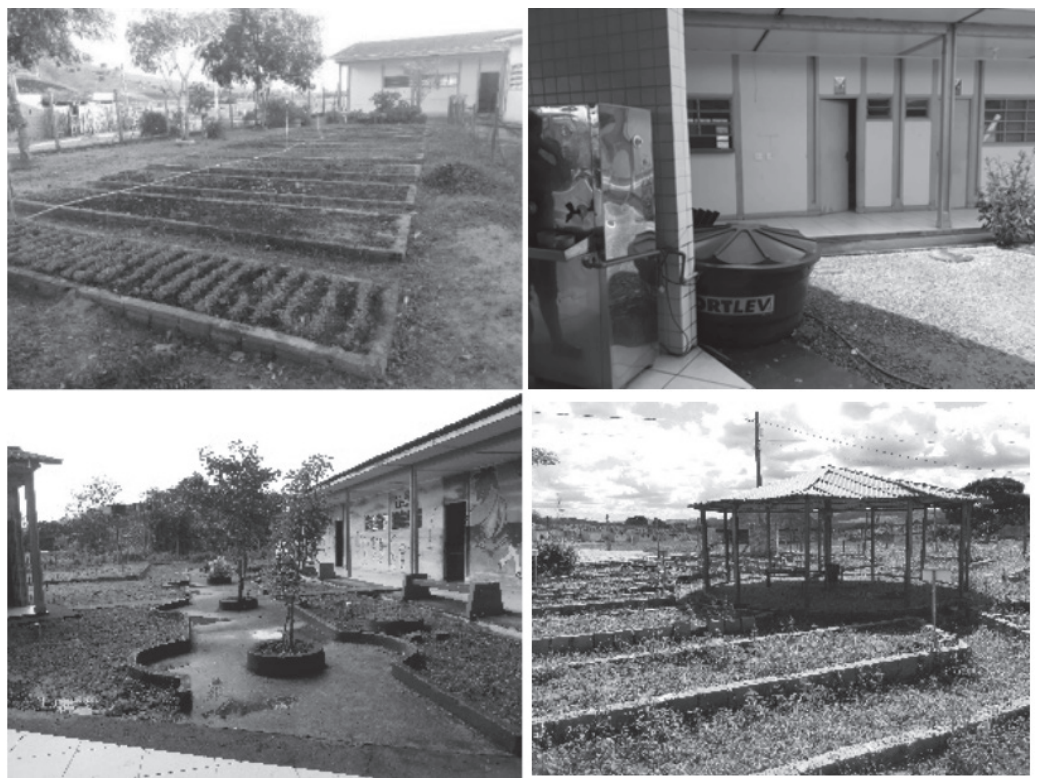

Fonte: Autora do estudo (2018).

\section{DIRETRIZES PAISAGÍSTICAS PARA AS ESCOLAS MUNICIPAIS DE UNIÃO DOS PALMARES}

Para a elaboração das diretrizes paisagísticas gerais, foram realizados levantamentos físicos e qualitativos em todas as unidades escolares no município de União dos Palmares, observando-se os seguintes aspectos:

3 Ecotécnicas consistem em intervenções tecnológicas no ambiente com base na compreensão dos processos naturais e foco na resolução de problemas com o menor custo energético e poupando recursos naturais. 
- Área disponível para o plantio de espécies vegetais;

- Tipo de solo;

- Vegetação existente;

- Exposição solar;

- Disponibilidade de água para irrigação;

- Características gerais do entorno;

- Destinação de uso.

A partir da análise das escolas visitadas, foram definidas as diretrizes gerais, aquelas que podem ser aplicadas nas diversas situações encontradas, possibilitando o melhoramento do ambiente escolar e proporcionar assim, um novo espaço de aprendizagem para os alunos, por meio da aplicação dos princípios da arquitetura paisagística, por meio da elaboração de uma cartilha informativa.

A partir das informações coletadas, foi elaborada uma tabela contendo as necessidades observadas por meio dos problemas encontrados e, as diretrizes que podem vir a solucioná-los:

Tabela 03 - Lista dos problemas e diretrizes

\begin{tabular}{|c|c|c|}
\hline $\mathbf{N}^{\circ}$ & PROBLEMAS & DIRETRIZES \\
\hline 1 & $\begin{array}{l}\text { Falta de pessoas que ajudem na } \\
\text { manutenção dos espaços verdes. }\end{array}$ & $\begin{array}{l}\text { Utilizar vegetação que não exija muita poda } \\
\text { e que seja de fácil manejo. }\end{array}$ \\
\hline 2 & $\begin{array}{l}\text { Alta absorção de calor das paredes } \\
\text { voltadas para o oeste. }\end{array}$ & $\begin{array}{c}\text { Proteger superfícies com espécies vegetais } \\
\text { específicas para este fim, em estruturas } \\
\text { próprias para isso. }\end{array}$ \\
\hline 3 & $\begin{array}{l}\text { Altas temperaturas no interior dos } \\
\text { ambientes escolares. }\end{array}$ & $\begin{array}{l}\text { Utilizar vegetação que projete sombra sobre } \\
\text { a edificação, com o uso de espécies arbóreas com } \\
\text { copa média ou alta e densa. }\end{array}$ \\
\hline 4 & $\begin{array}{l}\text { Falta de áreas com sombra para a } \\
\text { realização de atividades ao ar livre. }\end{array}$ & $\begin{array}{l}\text { Utilizar de vegetação de médio porte e mobiliário } \\
\text { adequado. }\end{array}$ \\
\hline 5 & $\begin{array}{c}\text { Ausência de espaços acessíveis para a } \\
\text { comunidade escolar. }\end{array}$ & $\begin{array}{l}\text { A partir das limitações do ambiente, propor } \\
\text { a criação de espaços que busquem a facilidade de } \\
\text { acesso e com boa visibilidade. }\end{array}$ \\
\hline 6 & $\begin{array}{l}\text { Carência de hortícolas e frutas na } \\
\text { merenda escolar. }\end{array}$ & $\begin{array}{c}\text { Propor espaços para o cultivo de frutas, verduras, } \\
\text { legumes e ervas; indicando algumas espécies para } \\
\text { os pomares e hortas. }\end{array}$ \\
\hline 7 & $\begin{array}{l}\text { Dificuldade de comprometimento } \\
\text { com o cuidado das áreas verdes. }\end{array}$ & $\begin{array}{l}\text { Criar métodos de engajamento de alunos e funcio- } \\
\text { nários no cuidado das áreas verdes. }\end{array}$ \\
\hline 8 & $\begin{array}{l}\text { Consumo de água potável onde o } \\
\text { uso não é imprescindível. }\end{array}$ & $\begin{array}{l}\text { Propor um sistema de reutilização de água de } \\
\text { bebedouros, calhas e condicionadores de ar. }\end{array}$ \\
\hline
\end{tabular}

Fonte: Autora do estudo (2018). 


\subsection{DIRETRIZ 1: UTLLIZAÇÃO DE ESPÉCIES DE FÁCIL MANEJO}

Os alunos e funcionários durante o tempo de cada um no ambiente escolar possuem deveres variados, tendo pouco tempo para ajudar na manutenção dos espaços verdes. Pensando nisso, deve-se utilizar vegetação que não exija muita poda e que seja de fácil manejo.

Portanto, o principal critério considerado para a escolha das espécies consistiu na seleção daquelas mais facilmente adaptáveis à região, preferindo-se as espécies nativas do Nordeste. Sendo assim, elas contribuem de forma mais eficiente para o equilíbrio ecológico, demandam menos manutenção, menos adubo e menos agrotóxicos.

Foram assim, sugeridas espécies vegetais divididas em diferentes categorias: espécies nativas (TABELA 4), frutíferas e hortícolas.

Tabela 4 - Lista de espécies vegetais nativas

\begin{tabular}{|c|c|}
\hline NOME COMUM & NOME CIENTíFICO \\
\hline Aroeira do sertão & Schinus terebinthifolius \\
\hline Ipê amarelo & Handroanthus albus \\
\hline Pau brasil & Paubrasilia echinata \\
\hline
\end{tabular}

Fonte: Autora do estudo (2018).

Além das espécies nativas, sugerimos as frutíferas (TABELA 5), por entendermos que elas desempenham um papel importante na melhoria da qualidade de vida da população, especialmente por fornecerem alimentos. Porém, deve-se ficar atento as escolhas das espécies de acordo com o espaço livre existente, devido ao seu crescimento.

As frutíferas necessitam de pouca manutenção, apesar de não serem facilmente encontradas em espaços públicos. Dessa forma, podem ser utilizadas na arborização das escolas, pois proporcionam floração atraente, perfume, sombra e frutos. É de grande importância o uso dessas espécies por seu caráter educativo.

Tabela 5 - Lista de espécies vegetais frutíferas

\begin{tabular}{|c|c|}
\hline NOME COMUM & NOME CIENTíFICO \\
\hline Aceroleira & Malpighia glabra \\
\hline Cajueiro & Anacardium occidentale \\
\hline Goiabeira & Psidium guajava \\
\hline Mamoeiro & Carica papaya \\
\hline Mangueira & Mangifera indica \\
\hline
\end{tabular}

Fonte: Autora do estudo (2018). 
Outras espécies que serão sugeridas são as hortícolas (TABELA 6), plantas de pequeno porte que podem ser cultivadas em hortas e jardins; demandam manutenção diária, porém, fornecem alimentos.

Tabela 6 - Lista de espécies vegetais hortícolas

\begin{tabular}{|c|c|c|}
\hline NOME COMUM & NOME CIENTíFICO & TIPO \\
\hline Abóbora & Cucurbita spp & Vegetais \\
\hline Alecrim & Rosmarinus officinalis & Temperos \\
\hline Alface & Lactuca sativa & Vegetais \\
\hline Beterraba & Beta vulgaris esculenta & Vegetais \\
\hline Boldo & Peumus boldus & Ervas \\
\hline Capim Santo & Cymbopogon citratus & Temperos \\
\hline Cebolinha & Allium schoenoprasum & Vegetais \\
\hline Cenoura & Daucus carota & Temperos \\
\hline Coentro & Coriandrum sativum & Ervas \\
\hline Erva cidreira & Melissa officinalis & Ervas \\
\hline Hortelã Grande & Plectranthus amboinicus & Temperos \\
\hline Manjericão & Ocimum basilicum & Vegetais \\
\hline Tomate & Solanum lycopersicum & Temperos \\
\hline Tomilho & Thymus vulgaris & \\
\hline
\end{tabular}

Fonte: Autora do estudo (2018).

\subsection{DIRETRIZ 2: PROTEÇÃO DE SUPERFíCIES ATRAVÉS DA IMPLANTACÇÃO DE ESPÉCIES VEGETAIS}

Com a necessidade de minimizar a absorção de calor das paredes voltadas para o oeste, temos a opção de criar jardins verticais. Para a criação destes indicamos o uso de garrafas PET, pois estas podem ser reaproveitadas para cultivo de vegetais de pequeno porte, temperos e ervas medicinais, presas em muros e paredes, as protegendo, sendo assim, uma forma popular de se apropriar de técnicas já existentes sustentáveis, viáveis e econômicas. 
As espécies sugeridas para isto são as hortícolas (TABELA 6), pois podem ser usadas no paisagismo para a decoração de jardins, explorando-se suas variadas formas, cores, texturas e aromas, dentre outras características que as tornam ornamentais. Além disso, são espécies alimentícias, fornecendo: vegetais, temperos e ervas que podem inclusive ser utilizadas com a finalidade medicinal nas escolas. Dessa forma, o paisagismo atinge uma papel ecológico e utilitário.

A maior parte dessas espécies vegetais necessita de cultivo ao sol pleno, por isso é imprescindível que sejam posicionas de forma a receber a luz para que a planta receba uma quantidade mínima de 03 a 04 horas de exposição solar por dia.

\subsection{DIRETRIZ 3: IMPLANTAÇÃO DE VEGETAÇ̃̃O NOS ESPAÇOS EXTERNOS PARA PROPORCIONAR SOMBRA A EDIFICAÇÃO}

É indicado, visando bloquear a radiação direta em ambientes internos às edificações escolares, o uso de espécies de médio e alto porte com copas densas como: aroeira, pau-brasil e mangueira; partindo-se da necessidade de fornecer condições ideais de temperatura. A arborização próxima à edificação se destaca como uma alternativa, não apenas ecologicamente correta, mas também, economicamente viável caso seja implantada corretamente.

0 uso da vegetação nas áreas externas, adjacentes ou integradas às edificações (pátios) proporciona o sombreamento para a edificação e de suas aberturas possibilitando a diminuição da temperatura no exterior próximo à edificação; enquanto o solo vegetado reduz a quantidade de poeira carregada pelo vento (GIVONI, 1981).

Atribuir à vegetação a capacidade de minimizar o calor e qualificar o microclima do interior das edificações é uma forma de proporcionar conforto térmico por meio da absorção da radiação solar e do resfriamento do ar que penetra no edifício.

\subsection{DIRETRIZ 4: PLANTIO DE ESPÉCIES VEGETAIS E IMPLANTAÇ̃̃O DE MOBILLÁRIO ADEQUADO}

Após observar que a maioria das escolas possuem grandes áreas verdes que não são utilizadas e que tradicionalmente fazem uso de espaços cobertos para o desenvolvimento de suas atividades acadêmicas, aplicamos essa diretriz, visando criar áreas sombreadas para a realização de atividades ao ar livre. Utilizando vegetação adequada e mobiliário apropriado é possível proporcionar sombra e conduzir a ventilação natural, fazendo com que seja um espaço agradável para a realização de atividades.

Para o mobiliário em espaços abertos nas escolas é importante a utilização de materiais ecologicamente corretos, que sejam de fácil manutenção e baixo custo, como a madeira plástica.

\subsection{DIRETRIZ 5: CRIAÇÃO DE ESPAÇOS ACESSÍVEIS}

Com a criação de novos espaços nas escolas, devemos repensar os trajetos de fluxos, estabelecendo caminhos de transição entre as paisagens com fluxos para o público e áreas de permanência.

Estes caminhos podem surgir de maneira natural ou intencional, possibilitando a contemplação 
do espaço envolvente. Porém, não deixando de lado os aspectos funcionais para todos que utilizam o espaço, assim, colocando em primeiro lugar a acessibilidade.

A acessibilidade é um conjunto de condições e possibilidades de alcance a todas as pessoas para a utilização dos espaços com segurança e autonomia. 0 mobiliário e os equipamentos devem proporcionar um maior conforto e independência a todos, como também proporcionar a pessoas com deficiência o direito de ir e vir a todos os locais da escola, participando de todas as atividades com o máximo de independência possível.

Os corredores e caminhos devem possuir largura suficiente para a quantidade de pessoas que os utilizam. 0 piso tem que ser antiderrapante, regular e estar em boas condições. Para possibilitar o acesso de pessoas em cadeira de rodas ou com dificuldade de locomoção, é necessário que existam rampas que interliguem os diferentes níveis, firmes e nivelados, com inclinação adequada para subir e descer.

\subsection{DIRETRIZ 6: CRIAÇÃO DE ESPAÇOS PARA O CULTIVO DE FRUTAS, VERDURAS, LEGUMES E ERVAS}

Esta diretriz, pensando no fornecimento de alimentos que possam vir a serem consumidos na própria escola, serve para indicar a criação de hortas e pomares que forneçam alimentos que possibilitem seu consumo na própria escola, pois, por meio das visitas as escolas constatou-se que algumas espécies vegetais não fazem parte da merenda escolar e que sua inclusão agregará sabor e qualidade.

As espécies que podem ser utilizadas para este fim são as hortícolas e frutíferas (TABELA 5; 6). Dentre as espécies hortícolas, os temperos e ervas devem ser priorizados devidos a sua ausência no fornecimento da merenda. Sendo muitas vezes incluídos no cardápio escolar por meio da doação de funcionários.

É possível ter horta e pomar para a realização de atividades educacionais. Estes espaços são fundamentais para que as crianças explorem o ambiente e tenham contato com a natureza; também mostrar aos alunos que em um pequeno espaço de terra é possível produzir muitos produtos.

\subsection{DIRETRIZ 7: PROMOÇÃO DO ENGAJAMENTO DE ALUNOS E FUNCIONÁRIIOS NO CUIDADO DAS ÁREAS VERDES}

Devido à escassez de tempo livre dos indivíduos no ambiente escolar (servidores e alunos), é necessário desenvolver metodologias para integrar a todos de maneira equilibrada. É preciso construir um sentimento de comprometimento que estimule neles a vontade de estar à serviço no cuidado das áreas verdes, e, de maneira especial, nas hortas e pomares.

A partir da opção por espécies de fácil manutenção, temos um componente que irá ajudá-los no serviço - não se tornando nada oneroso. A manutenção basicamente será realizada por meio de rega, limpeza e remoção de ervas daninhas (quando estas aparecerem); e, de forma menos periódica, replantio de algumas espécies após a colheita.

Montar um cronograma de rodízio por sala de aula seria uma forma de se pensar uma interação de funcionários e alunos, quando diariamente uma turma seria responsável, juntamente com um profissional da escola, pela manutenção. Tal profissional auxiliará os alunos e dará o suporte necessário. Recomendam-se para tal atividade que sejam separados 15 minutos diários, preferencialmente na primeira aula. 
A interação entre servidores e alunos neste momento proporciona a criação de vínculos e a construção de saberes visando uma melhor formação de uma consciência ambiental dos envolvidos.

\subsection{DIRETRIZ 8: IMPLANTAÇÃO DE SISTEMAS DE REUTILIZAÇ̃̃O DE ÁGUA}

Por se tratar de um bem natural que está cada vez mais raro e caro, reutilizar a água é de fundamental importância no ambiente escolar. Pensar em maneiras de seu reaproveitamento é uma forma de controlar perdas e evitar desperdícios, além de minimizar seu consumo. Esta pode ser poupada com o reuso para diversos fins como: utilizada em descargas sanitárias, lavagem dos pátios escolares e irrigação de áreas verdes.

Uma das melhores maneiras de reaproveitar a água é por meio de um sistema próprio de captação. Nas escolas podem ser feitos sistemas com utilização da água que é desperdiça dos bebedouros. Para isso, será necessária a instalação de canos que a captem e levem-na a um reservatório ou cisterna.

\section{CONCLUSÃO}

Por meio das visitas às escolas, foi possível elencar os problemas decorrentes do uso incorreto das áreas verdes; e assim, propor diretrizes que auxiliarão na correção desses espaços.

Com a definição das diretrizes foi possível construir a Cartilha de Paisagismo na Escola. E por meio dela, levar aos gestores e à comunidade escolar um material acessível que irá auxiliá-los na implantação e cuidado das áreas verdes.

Mais que entregar um subsídio informativo, o presente estudo preocupou-se em conhecer a realidade local e construir um material de fácil compreensão, adaptado a condição socioeconômica das unidades de ensino e sua limitação de recursos atualmente presentes.

Observou-se que uma grande parcela das escolas visitadas já possuíam o programa PDDE sustentável, já que são muito simples os requisitos para participação no mesmo, sem contar no incentivo financeiro que o programa traz para as instituições.

Por fim, propor ações voltadas para o meio ambiente nas escolas contribui com a formação humanística dos alunos, uma vez que estes crescem com uma visão ampliada do cuidado com o planeta; fornece material complementar à formação acadêmica e cumpre um papel social frente às necessidades ambientais.

\section{REFERÊNCIAS}

CAMPOS, Rochana; PÉRICLES, Cicero; TENÓRIO, Douglas Apratto. Enciclopédia: Municípios de Alagoas. 2. ed. Maceió: Instituto Arnon de Melo, 2006. 
IBGE. Censo 2010. Disponível em http://www.ibge. gov.br/cidadesat/topwindow.htm?.

Acesso em: 20 ago. 2018.

LEÃO, J. A. C. Considerações sobre o projeto escola aberta: perspectivas para uma agenda de lazer. Recife, 2005.

PACHECO, Fernanda Trescastro; SPONCHIADO, Margarete. Paisagismo e sustentabilidade para a promoção do bem estar da comunidade. Revista Guara, Espirito Santo, v. 5 n. 8, p. 131-139. 2017.

PONTALTI, Edna Sueli. Projeto de educação ambiental: Parque Cinturão Verde de Cianorte. 2005. Disponível em: http://www.apromac.org.br. Acesso em: 20 ago. 2018.

SANTOS, Susana Peres dos; GARDOLINSKI, Maria Terezinha Hanel Antoniazzi. A importância da educação ambiental nas escolas para a construção de uma sociedade sustentável. 2016.17p.
Recebido em: 30 de Março de 2018

Avaliado em: 5 de Maio de 2018

Aceito em: 10 de Agosto de 2018
A autenticidade desse artigo pode ser conferida no site https://periodicos set.edu.br

1 Doutoranda em Cidades pela Universidade Federal de Alagoas, Professora do Centro Universitário Tiradentes AL. Email: arianablopes@gmail.com 
